\title{
PENGARUH JARAK TERHADAP KUALITAS GAMBAR DALAM PENGIRIMAN CITRA DIGITAL MELALUI JARINGAN WIRELESS PADA KAMERA LS_Y201
}

\author{
Zhulfa Arif Hidayat, Denny Dermawan, Nurcahyani Dewi \\ Jurusan Teknik Informatika \\ Sekolah Tinggi Teknologi Adisutjipto Yogyakarta \\ informatika@stta.ac.id
}

\begin{abstract}
Digital image was needed us a medium of information that can be transmitted by cable or wireless media. To obtain digital images must use a tool such as a camera. Users can use the camera to get a digital image with the remote sensing method on an object in a particular place. In the daily activities, users can take advantages of the digital image (pictures or video) that are useful for media documentation, monitoring system in somewhere and others.The design of this tool using LS_Y201 camera to capture a digital image and wireless as a data transmission media. In this case a wireless media use Ultra High Frequency transmitter and receiver that support for remote sensing. Users run the tool through an application that is connected with a wireless media. This application is designed by Delphi7. Applications and wireless camera was made for simulation media of remote sensing and monitoring system in the blank spot area. The test result of applications and tools that use the Ultra High Frequency (wireless), can be viewed from a computer interface. In this case, the signal strength of the transmitter greatly affect the maximum distance that can be taken to make capture process. The test results are as follows: the best results at a distance of 10 meters $=011110102$ (12210); distance of 20 meters $=011100112(11510)$; distance of 30 meters $=011110102(12210)$; distance of 40 meters $=$ 011011112 (11110); distance of 50 meters $=011100102$ (11410). So the best distance to digital images transmission through a wireless networks are at a distance of 40 meters.
\end{abstract}

Keywords: Digital Image, Wireless, Interface

\section{Latar Belakang}

Citra dapat dimanfaatkan sebagai media infomasi sebagai kebutuhan tertentu misal sebagai media keamanan, media konsumsi dimana hal ini mengacu pada penginderaan jarak jauh yang bisa dikembangkan dalam dunia komputerisasi. Citra dapat disajikan sebagai bentuk informasi yang didapat dan ditampilkan melalui alat dan aplikasi yang dirancang khusus sebagai media penyalur citra melalui jaringan wireless maupun jaringan lainnya. Oleh karena itu dibutuhkan pengambilan citra melalui jaringan wireless.

\section{Tinjauan Pustaka}

Dalam sistem monitoring ini dijelaskan bahwa sistem ini dirancang menggunakan Wireless UHF Camera dan Wireless IP Camera sebagai media pengambil data berupa gambar yang akan dikirimkan kepada masyarakat sebagai media informasi. Wireless UHF Camera digunakan dalam mengambil gambar yang akan ditampilkan melalui media televisi sehingga bisa dilihat secara langsung oleh masyarakat pesisir dan Wireless IP Camera akan mengambil gambar yang kemudian akan disalurkan melalui media internet ke masyarakat luas. Ulasan 
singkat ini dikutip dari (Edi Sukriansyah, Hubbul Walidainy, Nasaruddin, 2012, Prosiding ISSN 2088-9984).

\section{Dasar Teori}

\section{Citra}

Citra adalah gambaran suatu gejala atau objek hasil rekaman dari sebuah sensor, baik dengan cara optik, elektro optik maupun elektronik. Citra merupakan salah satu jenis data hasil penginderaan jauh yang berupa data visual/gambar. Citra sering disebut dengan image atau imagery berupa gambar diam atau foto dan gambar bergerak dalam bentuk video.

\section{Wireless}

Wireless adalah teknologi yang menghubungkan dua piranti untuk proses transmisi data melalui media tanpa kabel. Wireless yang digunakan di jaringan komputer pada jarak jauh memakai pemancar berupa antena, transmitter-receiver maupun satelit. Bidang ini erat hubungannya dengan bidang telekomunikasi, teknologi informasi dan teknik komputer dengan menggunakan gelombang elektromagnetik sebagai media transmisi datanya.

\section{Penginderaan Jarak Jauh}

Penginderaan jarak jauh adalah pengukuran atau akuisisi data dari sebuah objek atau fenomena oleh sebuah alat yang tidak secara fisik melakukan kontak dengan objek tersebut dari jarak jauh, misalnya saja dari pesawat, pesawat luar angkasa, satelit, kapal, menara, bukit, bangunan dan lain-lain. Dalam implementasinya penginderaan jarak jauh bisa digunakan sebagai sistem pemantauan lalu lintas, media dokumentasi, sistem keamanan dan sebagainya.

\section{Perancangan Dan Analisa Sistem}

\section{Blok Diagram Sistem Alat}

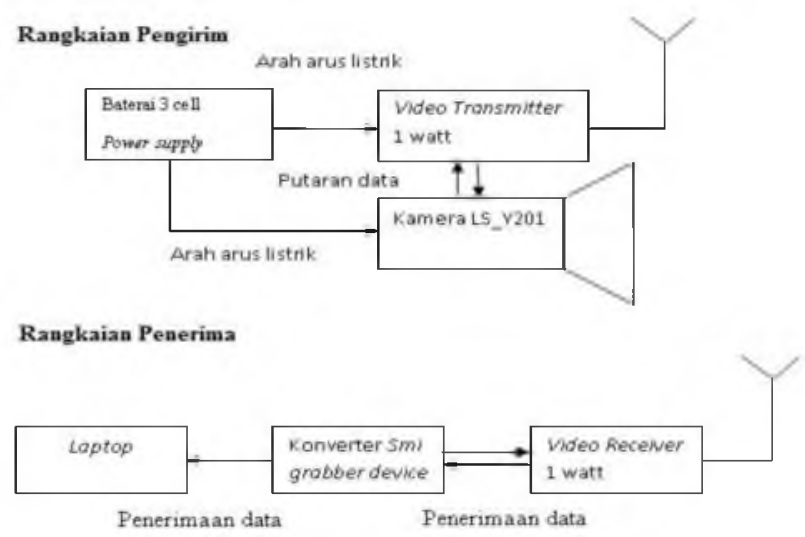

Gambar 1. Blok Diagram Sistem Alat

\section{Skematik Rangkaian}

Skematik rangkaian alat ada 2 yaitu rangkaian pengirim dan rangkaian penerima.

\section{Rangkaian Pengirim}

Dalam hal ini, rangkaian pengirim terdiri dari :

1. Rangkaian power supply 
2. Kamera

3. Transmitter

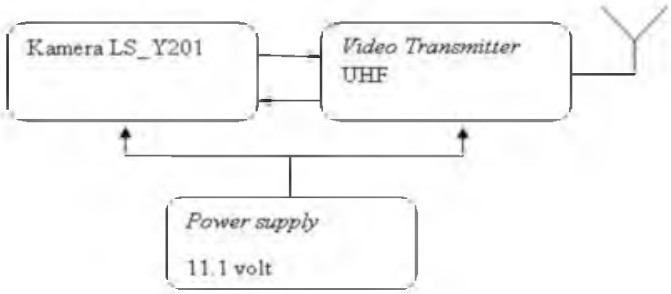

Gambar 2. Rangkaian Pengirim

\section{Rangkaian Penerima}

Rangkaian penerimanya terdiri dari 3 bagian yaitu :

1. Receiver

2. SMI Grabber Device

3. Laptop

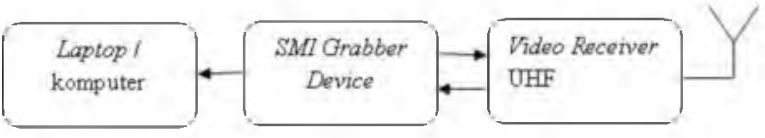

Gambar 3. Rangkaian Penerima

\section{Perancangan Entity Relationship Diagram (ERD)}

ERD adalah pemodelan data utama yang bertujuan untuk membantu mengorganisasikan data dalam suatu proyek ke dalam entitas-entitas dan menentukan hubungan antar entitas beserta atribut-atributnya.

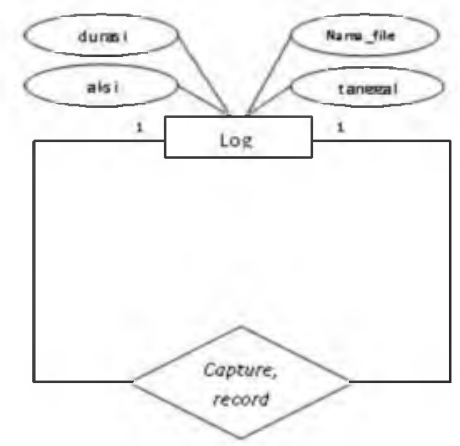

Gambar 4. ERD Aplikasi Capture Citra Digital Berbasis Wireless

\section{Flowchart Program Capture Citra}

Flowchart adalah gambaran dalam bentuk diagram alir dari algoritma-algoritma dalam suatu program yang menyatakan arah alur program tersebut. Melalui flowchart alur atau proses secara keseluruhan dari aplikasi bisa terlihat bagaimana urutan-urutannya. 


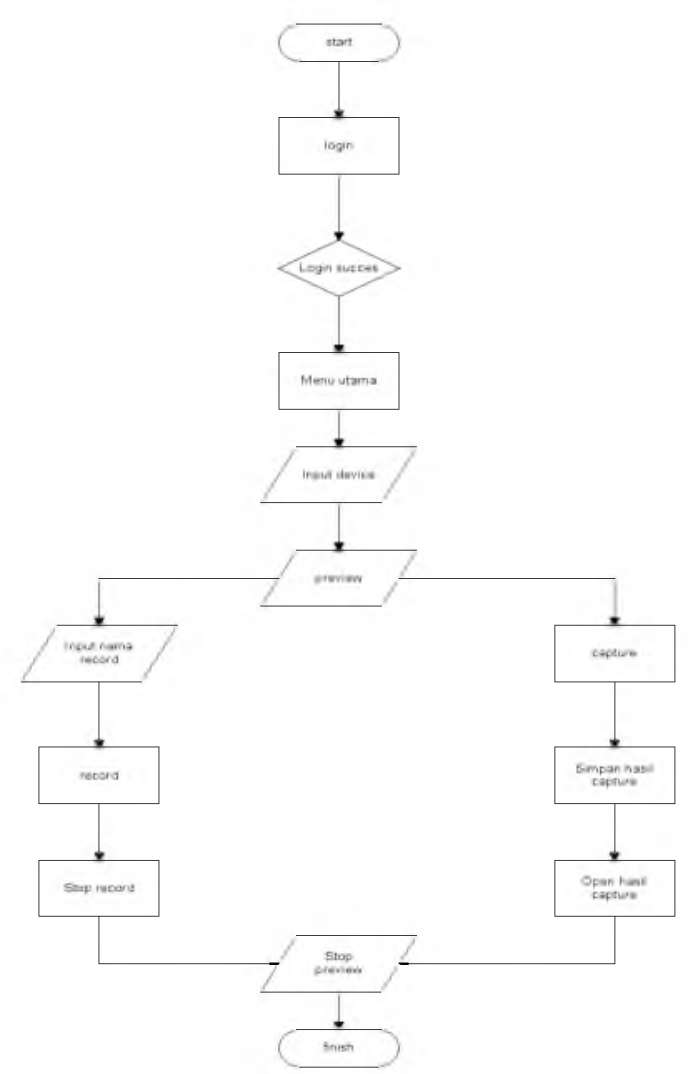

Gambar 5. Flowchart Aplikasi Capture Citra

\section{Implementasi dan Analisa Hasil}

\section{Ujicoba Hardware}

Hardware ini bekerja dengan cara mengambil gambar atau video dengan kamera LS_Y201 yang akan dikirimkan ke laptop sebagai media penyimpanan melalui gelombang UHF menggunakan transmitter dan receiver yang telah terhubung seperti pada Gambar 6.
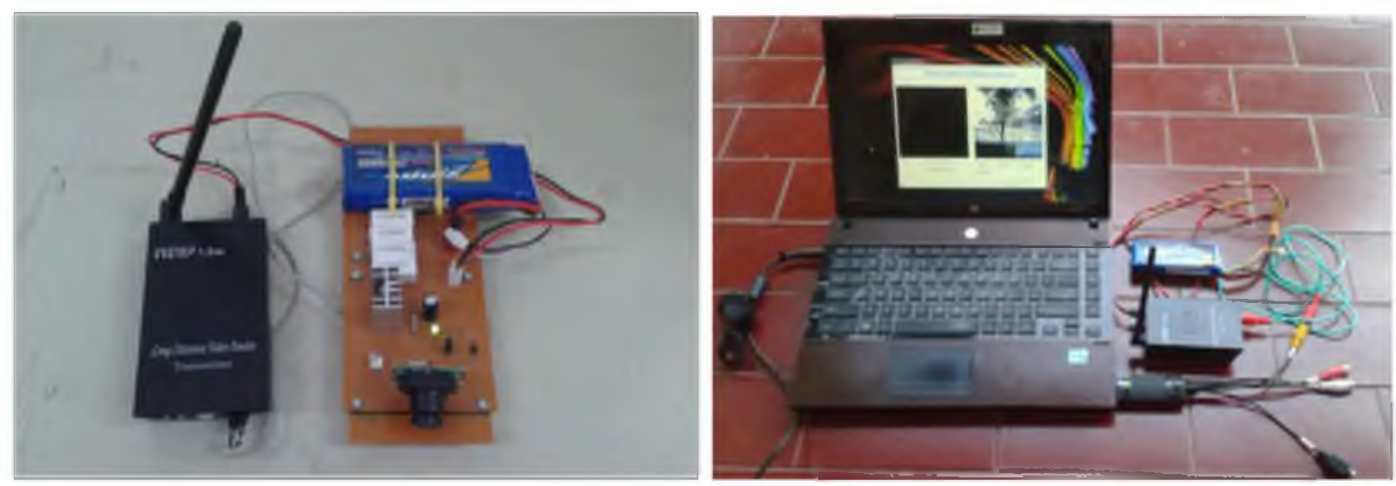

Gambar 6. Rangkaian pengirim dan penerima

\section{Ujicoba Software}

Software yang dibuat merupakan aplikasi untuk mengambil gambar atau video yang terkoneksi melalui gelombang radio UHF. Aplikasi terdiri dari form Login, form Menu Utama, form Log, form Tentang. 


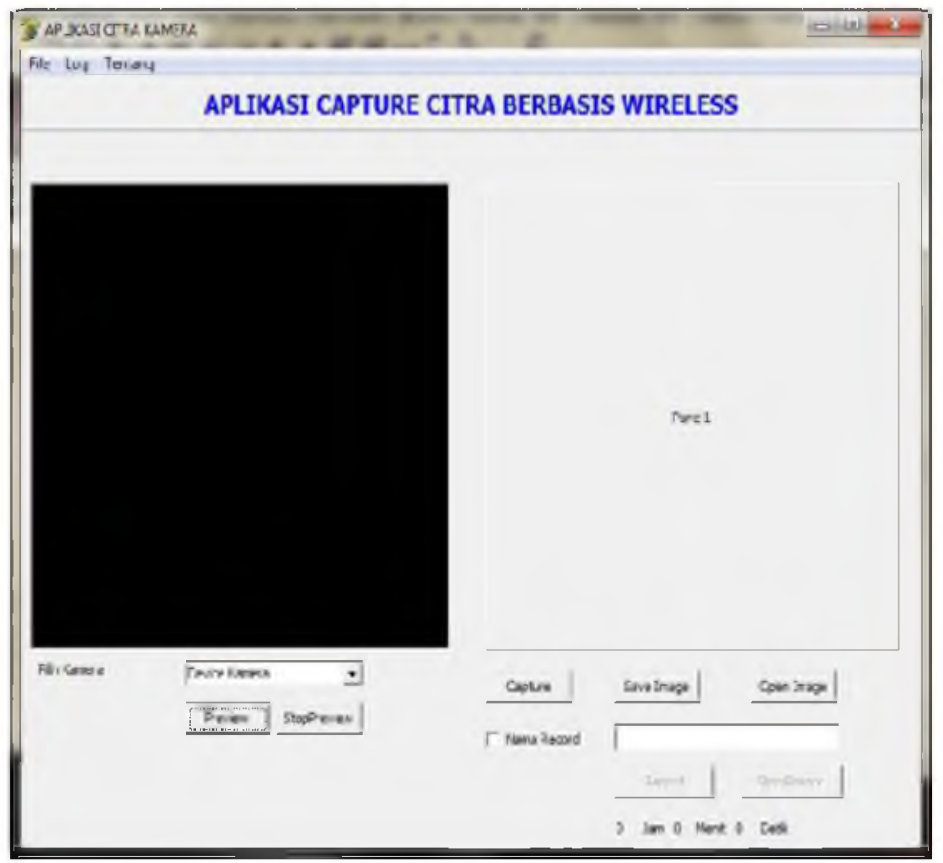

Gambar 7. Tampilan Menu Utama Aplikasi Capture Citra Berbasis Wireless

\section{Hasil Ujicoba dan Analisa Hasil}

Ujicoba dilakukan di sekitar area terbuka dengan cara mengambil gambar sebagai contoh dengan jarak yang berbeda-beda untuk melihat perbedaan kualitas gambar hasil dari pemantauan. Untuk lebih jelasnya dalam melihat perbedaan dari gambar yang dihasilkan bisa dilakukan dengan cara melihat nilai binary dari gambar tersebut yang kemudian membandingkannya.

1. Uji coba pada jarak 10 meter

$00101011 ; 01010000 ; 01000100 ; 01100011 ; 01111010 ; 01010000 ; 01101010 ; 01110100$ nilai desimalnya $=43 ; 80 ; 68 ; 99 ; 122 ; 80 ; 106 ; 116$.

2. Ujicoba pada jarak 20 meter

$00101011 ; 01010100 ; 00110000 ; 01110011$; $00110110 ; 01010011 ; 00110000$; 00110001 nilai desimalnya $=43 ; 84 ; 48 ; 115 ; 54 ; 83 ; 48 ; 49$.

3. Ujicoba pada jarak 30 meter

$00101011 ; 01010000 ; 01111010$; 00111000 ; 00111000 ; 01010001 ; 01000101 ; 01001001 nilai desimalnya $=43 ; 80 ; 122 ; 56 ; 56 ; 81 ; 69 ; 73$.

4. Ujicoba pada jarak 40 meter

$00101011 ; 01000100 ; 01100101 ; 01101111 ; 00110010 ; 01100110 ; 01101110 ; 00110110$ nilai desimalnya $=43 ; 68 ; 101 ; 111 ; 50 ; 102 ; 110 ; 54$.

5. Ujicoba pada jarak 50 meter

$00101011 ; 01010111 ; 00110011 ; 01101100 ; 01110010 ; 01011001 ; 01011000 ; 01101000$ nilai desimalnya $=43 ; 87 ; 51 ; 108 ; 114 ; 89 ; 88 ; 104$.

Hasil perhitungan nilai desimal dari binary gambar juga membuktikan adanya perbedaan kualitas dari gambar tersebut. Hal ini membuktikan jika jarak mempengaruhi kualitas dari gambar yang dikirim melalui jaringan wireless yang diambil menggunakan kamera LS_Y201. Dari ujicoba yang dilakukan bisa didapatkan hasil terbaik pada jarak 10 meter $=011110102(12210) ;$ jarak 20 meter $=011100112(11510) ;$ jarak 30 meter $=011110102$ $(12210)$; jarak 40 meter $=011011112(11110)$; jarak 50 meter $=011100102(11410)$. Sehingga 
jarak terbaik untuk pengiriman citra digital melalui jaringan wireless adalah pada jarak 40 meter yang merupakan titik fokus dari kamera wireless.

\section{Kesimpulan dan Saran}

\section{Kesimpulan}

Dari hasil ujicoba yang sudah dilakukan dapat dibuat kesimpulan sebagai berikut:

1. Aplikasi dan alat bisa digunakan untuk simulasi penginderaan jarak jauh dengan menggunakan gelombang Ultra High Frequency, data citra digital berupa gambar atau video bisa dikirimkan melalui video transmitter dan diterima oleh video receiver yang bisa dilihat di laptop.

2. Aplikasi dan alat juga bisa digunakan untuk monitoring tempat di blank spot area, dimana kekuatan sinyal gelombang radio Ultra High Frequency berpengaruh terhadap jarak yang bisa dicapai untuk melakukan proses transmisi data sesuai keadaan lokasi saat pengambilan citra digital.

3. Jarak antara video transmitter ke video receiver terbukti berpengaruh terhadap kualitas gambar yang diambil menggunakan kamera LS_Y201, dimana binary dari setiap gambar yang dihasilkan berbeda dan dibuktikan dengan cara menghitung nilai desimal dari binary gambar hasil ujicoba.

\section{Saran}

Untuk meningkatkan kinerja dan hasil dari sistem aplikasi capture citra berbasis wireless diperlukan beberapa pengembangan antara lain:

1. Aplikasi dan alat ini memerlukan kamera dengan kualitas resolusi yang baik agar gambar atau video yang dihasilkan berwarna dan jelas.

2. Agar bisa digunakan ketika dalam kondisi gelap bisa juga menggunakan kamera infrared yang mampu mengambil gambar atau video ketika tidak ada cahaya.

3. Video transmitter dan video receiver sinyal gelombang Ultra High Frequency yang digunakan perlu diperbaharui dengan daya yang lebih besar supaya bisa menjangkau jarak maksimum yang lebih jauh.

\section{Daftar Pustaka}

Ahmad Balza, 2011. Pemrograman Delphi untuk Aplikasi Mesin Visi Menggunakan Webcam. Graha Media : Yogyakarta.

Charibaldi Novrido, Dessyanto Boedi Prasetyo, Jatu Wiedyasari, 2009. Aplikasi Kamera Video untuk Pemantau Keadaan Suatu Ruangan. Prosiding ISSN 1979-2328. Seminar Nasional Informatika 2009. UPN Veteran Yogyakarta : Yogyakarta.

Fadlisyah Rizal, 2011. Pemrograman Computer Vision pada Video Menggunakan Delphi + Vision Lab VCL 4.0.1. Graha Ilmu : Yogyakarta.

Hantoro Gunadi Dwi, 2009. WIFI(Wireless LAN) Jaringan Komputer Tanpa Kabel. Informatika : Bandung.

Kurniawan Wahid, 2012. Perancangan Aplikasi untuk Peralatan Pemantau Suhu Menggunakan Radio Frekuensi. Compiler Jurnal Adisutjipto Informatics Society Volume I, Nomor 2, 2012 : Yogyakarta.

Putra Samuel Mahatma, Handoko, Rika Mandasari, Bino Pramana Bestari, 2010. Analisis dan Perancangan Aplikasi Monitoring IP Camera Menggunakan Protokol HTTP pada Mobile Phone. 
Prosiding ISSN 1907-5022. Seminar Nasional Aplikasi Teknologi Informasi 2010. Yogyakarta, 19 Juni 2010 : Yogyakarta.

Sukriansyah Edi, Hubbul Walidainy, Nasaruddin, 2012. Sistem Monitoring dan Informasi Peringatan Tsunami Berbasis Wireless UHF Camera dan Wireless IP Camera. Prosiding ISSN 2088-9984. Seminar Nasional dan Ekspo Teknik Elektro 2012 : Medan.

Sulistiyanti S. Ratna, Warsito, Andi Darmawan, 2008. Rancang Bangun Model Sistem Pemantauan Tinggi Muka Air Sungai Menggunakan Telemetri Radio . Jurnal Rekayasa dan Teknologi Elektro Volume 2, Nomor 1, Januari 2008 Universitas Lampung : Lampung.

Sulistiyanto Debby Wahyu, 2012. Sistem Aplikasi Monitoring Ruangan Berbasis Webcam. Tugas Akhir Teknik Informatika Sekolah Tinggi Teknologi Adisutjipto : Yogyakarta.

Syafrizal Melwin, 2005. Pengantar Jaringan Komputer. Andi Offset : Yogyakarta.

\section{Internet Resources}

http://aman-auliarahman.blogspot.com/2012/10/tutorial - cara - pemula - belajar -program.html, diakses pada tanggal 23 Maret 2013.

http://daneytech.com. E-book : Kurniawan Dayat, 2011. Mahir Pemrograman Webcam dengan Delphi, diakses pada tanggal 26 April 2013.

http:/hwww.digi-ware.com, diakses pada tanggal 11 Desember 2012.

http://ilmukomputer.org/wp - content/uploads /2011/11/taufik - capture -foto - vidgrab.pdf diakses pada tanggal 23 Maret 2013.

http://wwww.klinik-robot.com, diakses pada tanggal 20 Desember 2012.

http://wwww.mercubuana.ac.id/file/jurnal\%20murdifin.pdf, diakses pada tanggal 21 Juli 2013. 
Zhulfa Arif Hidayat, Denny Dermawan, Nurcahyani Dewi 